\title{
ITALIAN HYBRID FIRE PREVENTION CODE
}

\author{
PIERGIACOMO CANCELLIERE ${ }^{1}$, MARA LOMBARDI $^{2}$, LUCA PONTICELLI $^{1}$, EMANULE GISSI $^{1}$ \\ GIORDANA GAI ${ }^{2} \&$ MAURO CACIOLAI ${ }^{1}$ \\ ${ }^{1}$ Ministry of Interior, Italian National Fire Rescue and Service - CNVVF - Rome, Italy \\ ${ }^{2}$ Civil \& Industrial Engineering Faculty, Sapienza University of Rome, Italy
}

\begin{abstract}
Fire safety of residential buildings and activities subjected to fire inspection are difficult tasks, especially when the safety targets have to be adopted in pre-existing buildings or in activities that are going to be modified into more complex ones. Generally, these circumstances show more constraints and it can be difficult to achieve an acceptable level of fire residual risk by prescriptive based fire regulations. Therefore, the Italian National Fire Rescue and Service in charge of fire safety, in August 2015, issued a new Fire Prevention Code whose design methodology is more oriented to fire performance based design rather than prescriptive fire codes. The flexibility of this new fire design methodology offers a very complex tool for experts in order to design fire safety measures and strategies for buildings and activities subjected to fire inspection. The present paper aims to highlight the contents and the fire safety strategy design methodology of the new Italian Fire Prevention Code.
\end{abstract}

Keywords: IFC, fire codes, fire regulations, fire safety, performance base design.

\section{INTRODUCTION}

To reduce risks and achieve acceptable levels of safety, fire codes and regulations play a fundamental role both in buildings and high hazard facilities. Most of the Italian activities subjected to fire inspection and listed in the annexe 1 of the Decree DPR 151/2011 [1] - such as stores, malls, schools, hospitals, car parking facilities and industrial buildings - are subject to prescriptive fire safety codes. The prescriptive fire codes are basically composed of certain requirements which attempt to specify all the different components and devices of the system to provide fire safety for a building or an industrial activity. Nevertheless, the contribution of each requirement to the level of safety provided by the system is not known and the interactions between the components are not generally known or taken into account [2]. In addition, when the safety targets have to be satisfied in pre-existing buildings or in activities that are going to be modified into more complex ones, there are more constraints to cope with and it could be difficult to achieve an acceptable level of fire risk using prescriptive-based fire codes and regulations. These inherent deficiencies lead to a lack of flexibility, conservative outcomes and unnecessary cost burdens.

On August $20^{\text {th }}, 2015$, the Italian Home Office released the Ministerial Decree of August $3^{\text {rd }}, 2015$, that contains a new approach to the fire safety design of activities subjected to fire inspection. The technical Ministerial Decree is titled "Approval of fire prevention technical standards, pursuant to Article 15 of Legislative Decree 139 of March 8, 2006", but is commonly recognised among Italian fire officers and practitioners as the Italian Fire Prevention Code (IFC) [3].

The IFC was developed by fire brigades, safety officer engineers and fire practitioner experts to simplify and rationalise the fire safety design of activities subjected to fire inspection. The IFC, following the fire safety engineering principles, sees the process of fire safety design considering the system as a whole by focusing on the safety targets whether they are life safety, property loss, business interruption, environmental damage or heritage preservation. 
The IFC gives a new approach to fire safety design. Supported by a quantitative fire risk assessment, the new design methodology can guide the practitioner during the fire design process in choosing the best fire provision to reduce and mitigate the assessed fire risk to an acceptable level.

The international state of the art of fire design codes, such as but not limited to the BS 9999:2008 "Code of practice for fire safety in the design, management and use of buildings" [4], the NFPA 101 "Life Safety Code" [5], and the International Fire Code 2009 [6], have been considered during the developing stage of the IFC.

Nowadays, actual studies and experiments for understanding fire-related phenomena increase the capability of the fire engineering community to assess and predict the performance of structures and protection systems when exposed to a fire event [7]. The use of analytical tools such as empirical models, finite element analysis, and computational fluid dynamics, in conjunction with bench top and full-scale testing has improved the ability of fire prevention operator to develop performance-based solutions to challenging fire safety design of high-risk industrial activities or complex buildings.

The new fire design tool also takes into strong consideration the overall shifting of fire safety regulations from an approach based on prescriptive requirements to an approach more oriented to performance-based design (PBD) [8].

The fundamental assumptions of the IFC fire regulation are:

a) in ordinary conditions (no arson, no catastrophic situations), a break out of a fire in an activity could happen only in one point of ignition;

b) in any safety design, the risk of fire cannot be reduced to zero; the fire-safety prevention, protection and management measures provided following the IFC fire design process ensure a proper selection of the measure that minimizes the risk of fire in terms of both occurrence and damages, at a level that could be considered as an acceptable level of safety.

This paper highlights and discusses principles and methods proposed by the IFC for the fire safety design of activities subjected to fire approval and inspection.

\section{FIRE SAFETY DESIGN PROCESS}

The prescriptive fire design approach assumes that by following all the rules and requirements of the applicable regulations, the achieved fire safety level is acceptable [9], [10].

Moreover, advance structural engineering as well as material science innovation technologies satisfy the architectural demands to build up complex buildings that cannot comply with fire prescriptive codes. In order to assure an acceptable level of fire safety, risk-based methods could provide an opportunity to determine the quantitative safety level. The main advantage of the risk based method is the hazard versus safeguard determination both as probability and damage [11].

The general design of the IFC fire risk assessment and mitigation strategy is based on the following principles. The first one is the overall applicability of the design procedure that should be specific for each activity subjected to fire inspection. The IFC method is oriented to "Simplicity": given different choices to achieve the same safety level, the simpler one and the more easily achievable solution shall be preferred, also taking into account the maintenance features.

The design is "module" oriented: the complexity of the fire design is split into easily accessible modules, which guide the designer towards the appropriate solutions for any specific activities. 
Moreover, IFC has also been standardised and integrated to the fire-safety and fire-protection language of international standards. The code is also fully inclusive: different disabilities (e.g. motor, sensory, cognitive ...), temporary or permanent, of the occupants shall be considered as an integral part of the fire-safety design.

Furthermore, the overall design process of the IFC is based on the latest international and national scientific research in the field of fire safety and protection. Lastly, the IFC was thought to be easily "updatable": the document has been drafted in a format that can be easily kept up to date with the continuous improvements in terms of technologies and knowledge available in fire safety science.

The IFC design method is very "Flexible": for each fire-safety project it gives design solutions that are semi-performance based (the so called "deemed-to-satisfy solutions"). These compliant solutions contain prescriptive examples of materials, products, design factors, construction and installation methods, which - if adopted - comply with the performance requirements of the IFC.

If the deemed-to-satisfy solution cannot be put in place, the IFC offers performance-based solutions called "alternative solutions". The alternative solution is any solution that can meet the IFC performance requirements, other than a deemed-to-satisfy solution, using the following allowed methods:

- $\quad$ Fire Safety Engineering;

- Innovative technologies, products and systems;

- Alternative, authoritative fire codes or regulations, national or international.

The alternative solution implies that the requested level of performance is in any case achieved.

The IFC risk assessment starts from the context description by pointing out the operational and environmental peculiarity of the activity. The second step is identifying and analysing the activity risks by means of a systematic analysis based on fire hazard related factors. Then it is necessary to prioritise the risks in order to tackle them by means of fire prevention measures, protections and management strategies. The final goal of the IFC is aimed at saving lives, protecting property and safeguarding the environment in case of fire. According to the IFC document, the risk assessment is completed by the evaluation of the following simplified parameters:

- $\quad \mathrm{R}_{\text {life, }}$, risk profile concerning the safety of human life;

- $\mathrm{R}_{\text {pro, }}$, risk profile concerning the property protection;

- $\mathrm{R}_{\mathrm{env}}$, risk profile concerning the protection of the environment from the effects of the fire.

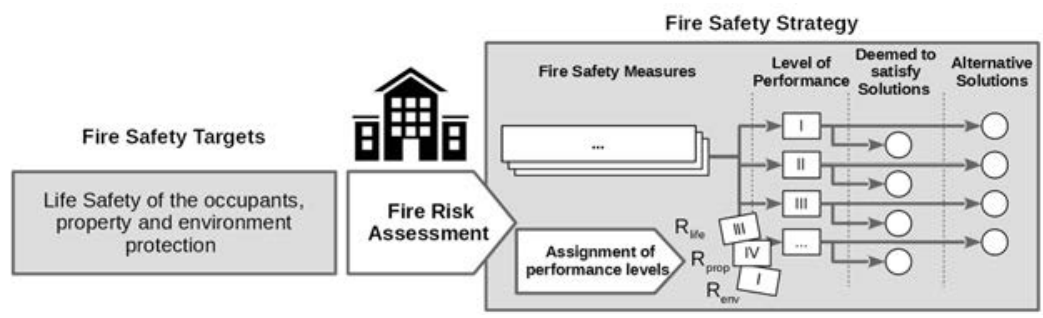

Figure 1: IFC fire safety design. 
The fire risk profile connected to life safety $-R_{\text {life }}-$ is evaluated as a function of the growth rate of a fire in a building compartment. The behaviour of building occupants in response to a fire is defined. The fire growth is a square type (typical parameter varies from 1, representing a slow fire growth, to 4, oran ultrafast fire growth). The occupant characteristics are summarized into the following groups:

- A occupants awake and familiar;

- B occupants awake but unfamiliar;

- C occupants that could be asleep;

- D occupants receiving medical care;

- E walking occupants (stations, tunnels).

The occupancy characteristics chosen by the IFC are the same of those contained in BS 9999 [4]. $\mathrm{R}_{\text {pror }}$ is based on the building's strategic nature or heritage, cultural, architectonic or artistic value, coupled to the significance of the building contents, such as business continuities or property protection. The last simplified risk parameter $\mathrm{R}_{\mathrm{env}}$ takes into consideration the risk of environmental damage or environmental contamination during and after the outbreak of a fire. $R_{\text {env }}$ is assessed also taking into account the emergency response management, and it is usually mitigated by the application of the fire safety measures connected to the $\mathrm{R}_{\text {life }}$ and $\mathrm{R}_{\text {pror }}$ risk profiles for civil activities such as residential buildings, schools, theatres and shopping malls where the quantity of hazardous substances can be assumed as not significant. Fig. 1 highlights the general fire safety design method proposed by the IFC.

\section{IFC RISK ASSESSMENT AND FIRE SAFETY MEASURES: PERFORMANCE LEVEL}

The IFC method requires the selection and application of the proposed fire safety measures following the risk assessment outcomes. In particular, the fire safety strategy can be seen as a safety path that the designer has to follow to achieve the primary objectives of fire safety: life safety, property protection and the safeguarding of the environment. These safety targets can be achieved by integrating all of the IFC fire measures. Therefore, the fire safety path is split into ten "steps" that are the fire safety measures. The IFC safety measures are as follows:

- $\quad$ S1 Reaction to fire;

- $\quad$ S2 Fire Resistance;

- S3 Fire Compartmentation;

- S4 Means of Egress;

- S5 Fire Safety Management;

- S6 Fire control and suppression Systems;

- $\quad$ S7 Fire Detection and Alarm Systems;

- $\quad$ S8 Smoke Management;

- S9 Fire Rescue Team Safety Provisions and Measures;

- S10 Fire Safety of ordinary technological building plants. 


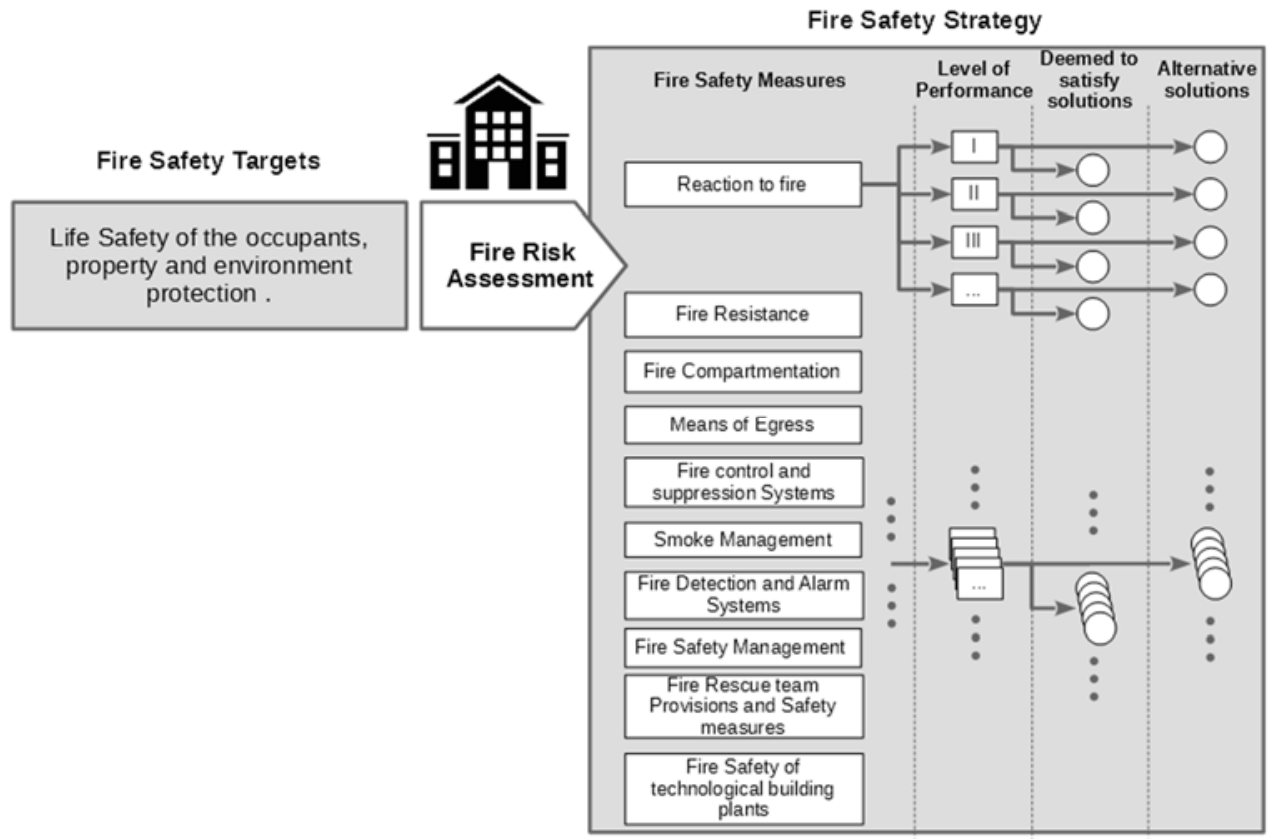

Figure 2: IFC fire measures performance level.

For each above listed measure, the fire risk assessment outcomes lead to the choice of a performance level and, as a consequence, to the selection of the relevant technical fire safety solutions. The technical solutions can be indifferently selected by the practitioner using a (semi-)prescriptive or a performance-based approach. In case of the prescriptive approach (the traditional and most preferred way currently used in Italy), these solutions, whose technical details are written in the IFC, are called "deemed-to-satisfy" solutions. A deemedto-satisfy solution implies the fulfilment of the requested safety level. In the second case, these solutions are called "alternative solutions" because they can be chosen instead of the deemed-to-satisfy solutions. The designer has to demonstrate the fulfilment of the requested safety level given the required performance level, therefore the rules of fire science shall be applied. Fig. 2 depicts the IFC process to select performance levels.

\section{AIMING FOR SATISFYING PERFORMANCE SOLUTIONS}

As well recognized, the Fire Risk Assessment is the most important factor of the IFC method. Each fire safety measure can fully achieve the required level of performance both implementing a deemed-to-satisfy solution, or recurring to an alternative solution. The availability of semi-performance-based solutions coupled to alternative ones elect the IFC code as a hybrid fire code more oriented to performance-based solution rather than prescriptive ones. In the following, in order to explain the IFC design method, the selection and fulfillment of the fire safety measure S6 is described. The need for portable, manual and automatic fire suppression systems can be selected using Chapter S6. In fact, Chapter S6 deals with the provision for controlling and suppressing a fire in an activity. Active fire protection measures are divided into five levels of performance; the first one is not suitable 
Table 1: S6 Performance levels.

\begin{tabular}{|c|l|}
\hline $\begin{array}{c}\text { Performance } \\
\text { requirement }\end{array}$ & \\
\hline I & No provisions required \\
\hline II & Basic protection (control requirements of fire size) \\
\hline III & Basic protection and Manual protection \\
\hline IV & $\begin{array}{l}\text { Basic protection, Manual protection and Automatic suppression system only } \\
\text { extended to selected hazardous zones }\end{array}$ \\
\hline V & $\begin{array}{l}\text { Basic protection, Manual protection and Automatic suppression system extended } \\
\text { to the entire building or activity. }\end{array}$ \\
\hline
\end{tabular}

for activity subjected to fire inspections as no provision is required. Level II wants only a basic protection in order to contrast a starting fire (a fire of a limited size); level III requires the addition of a manual system to mitigate a fire developing in a compartment. The performance level IV requires all of the protection measures provided by level III, in addition to an automatic suppression system covering only selected hazardous areas of the activity. Finally, the highest level of active protection measures implies selecting all the portable and manual measures and also extending the automatic suppression system to the entire building or activity. Table 1 summarizes the S6 level of performances of fire control and suppression safety measure.

The chapter S6 also contains generally accepted criteria to be followed in order to select the performance level according to the risks profile $\mathrm{R}_{\text {life }}, \mathrm{R}_{\text {prop }}, \mathrm{R}_{\text {env }}$ and other hazardous parameters resulting from the assessed fire risk of the activity. Table 2 describes the performance level compliant with acceptability criteria. Once the performance level is set following the result of the risk assessment, the designer knows the purpose of the selected level of performance.

The required safety level and its purpose lead the designer to select the correlated technical solution. In case of "deemed-to-satisfy solutions", the IFC provides some prescriptive technical measures for the performance requirement levels II, III IV and V. Basic protection has the objective of ensuring the use of effective firefighting equipment at the initial phase of a fire, before it propagates to other portions of the activity. The types of extinguishers installed must be selected based on the classes of fires (e.g. class A fire extinguishers, ABC multi-purpose fire extinguishers), determined according to the outcomes of risk assessment. Following the deemed-to-satisfy solutions, the basic protection - Level II of performance is fulfilled for a class A fire by placing a portable fire extinguisher sufficient for each 100 $\mathrm{m}^{2}$ of the protected area, with at least half of the fire extinguishers rated 34A, while the others can be $21 \mathrm{~A}$ The number of class B extinguishers that should be installed, shall be such that the total extinguishing capacity $\mathrm{CB}$ is not less than the minimum extinguishing capacity $\mathrm{CB}_{\min }=144 \cdot \mathrm{S}$, where $\mathrm{S}$ is the protected area expressed in square meters. In addition, at least $50 \%$ of $\mathrm{CB}_{\min }$ must be provided by extinguishers with an extinguishing capacity not less than $144 \mathrm{~B}$. Finally, the protected area must show a usable fire extinguisher reachability within a distance of $20 \mathrm{~m}$. Fire extinguishers must always be ready for immediate use: therefore they must be easily visible and reachable, near the exits from the floor and along escape routes, and near specific risk areas. If the fire risk assessment shows the need for installing fire extinguishers effective on several fire classes (A, B, F.etc.), it is proposed that the number of different types of extinguisher be minimized according to the maximum reaching distances. 
Table 2: S6 performance level vs compliant criteria.

\begin{tabular}{|c|c|}
\hline $\begin{array}{l}\text { Performance } \\
\text { requirement }\end{array}$ & Assignment criteria \\
\hline $\mathrm{I}$ & Not allowed for fire inspection activities \\
\hline II & 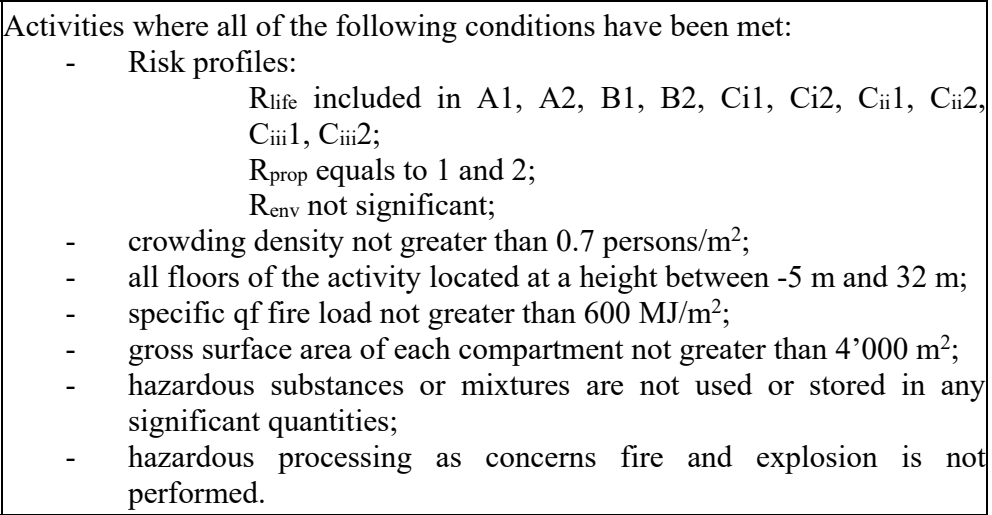 \\
\hline III & Activities not included in the other assignment criteria. \\
\hline IV & $\begin{array}{l}\text { According to the results of the risk assessment e.g. activity with high crowding, } \\
\text { activity with complex geometries or underground floors, high specific qf fire } \\
\text { load, hazardous substances or mixtures (significant quantities), hazardous } \\
\text { processing as concerns fire. }\end{array}$ \\
\hline $\mathrm{V}$ & $\begin{array}{l}\text { If requested by the owner, provided for by project technical specifications, } \\
\text { required by the authorities for strategic buildings safety, or required by vertical } \\
\text { technical fire safety regulations. }\end{array}$ \\
\hline
\end{tabular}

The S6 performance level III implements as a deemed-to-satisfy solution the installation of a hydrant system extended to the entire activity or, at least, to a single building compartment. This deemed-to-satisfy solution requires a fire hydrant system designed according to the UNI 10779 Italian national fire hydrant standard, where hazard levels, types of protection and water-supply characteristics shall be set by the designer based on the outcomes of the fire risk assessment. The deemed to satisfy solution for S6 performance level IV requires, other than fire extinguishers and hydrant systems, an automatic fire suppression system extended to selected building zones.

The selection of the automatic protected zone is carried out on the basis of the outcomes of the fire risk assessment, also taking into account the effect of the extinguishing devices, as well as considering the size, power and topology of fires that should be controlled or suppressed. The deemed-to-satisfy solution for the design of an automatic suppression system merely requires the employment of the Italian and European technical standards, such as UNI EN 12845 for sprinklers, UNI EN 150004-1 for gas extinguisher systems and other relevant standards or technical specifications. Since the status of the selected automatic suppression system must be supervised by the building fire management, in the case that a fire alarm is installed, the relevant status and surveillance signals of the automatic suppression system have been connected and processed by the central panel of the fire alarm system. If no fire alarm is installed, the emergency management measures must be set up (e.g. broadcast of the alarms to the occupants, procedure check by the emergency management staff). to signal the status of the automatic fire control or suppression system. 
The higher S6 performance level V is fulfilled by extending the automatic fire control or suppression system to the entire building or activity.

\section{ALTERNATIVE "PERFORMANCE-BASED" SOLUTIONS}

For all the aforementioned deemed-to-satisfy solutions proposed by the IFC, an alternative solution can be adopted. As shown in Table 3, IFC offers three ordinary fire safety design methods in order to demonstrate the achievement of the connected performance level requirements. These ordinary fire design methods can be also adopted in order to select another fire measure performance level rather than the level selected by using the general criteria.

Therefore, alternative solutions can be adopted following the application of international fire safety standards, or innovative products and technology. In addition, the more suitable design method is the Fire Safety Engineering (FSE) design. In fact, the section M of the IFC is fully dedicated to the FSE Performance-Based Approach. Three chapters compose the M section, whose content describes the main phases to a correct performance-based approach and the details to be included in the documentation for the approval of the fire safety project. More technical engineering aspects are also contained in the section, including best practices and international references for each specific aspect [12]-[15].

\subsection{M1, methodology of fire safety performance-based approach}

The chapter M1 describes the minimum content of the additional fire safety documentation in case of a performance-based approach that has to be delivered with the usual design reports (structural, mechanical, etc.). Essentially, a technical report and a program for the fire safety management need to be arranged and approved. In addition to this, two phases of the design process are individuated and described, in order to give an exhaustive explanation of the sense of the fire performance-based approach to fire designers. The first phase is called "preliminary analysis" and is needed to identify the more realistic fire risk conditions (fire scenarios) and the safety objectives to be achieved as well as the performance thresholds to be verified. This initial phase must be followed by a second phase called "quantitative analysis" where the effects of the fire, in terms of significant numerical parameters, need to be compared with the thresholds previously identified.

Table 3: Ordinary fire-safety design methods.

\begin{tabular}{|c|l|}
\hline Fire Design Method & \multicolumn{1}{|c|}{ Description of the application limits } \\
\hline $\begin{array}{c}\text { Application of } \\
\text { standards or technical } \\
\text { documents }\end{array}$ & $\begin{array}{l}\text { The designer must apply standards or technical documents issued by } \\
\text { internationally recognised fire-safety organisations. The selected standard or technical } \\
\text { document must be fully implemented by means of solutions, configurations, materials } \\
\text { and components recommended in the standards or technical documents, by specifically } \\
\text { highlighting the suitability for each chosen configuration. }\end{array}$ \\
\hline $\begin{array}{c}\text { Innovative products and } \\
\text { technologies }\end{array}$ & $\begin{array}{l}\text { Innovative products or technologies are allowed when the compliance for the fire safety } \\
\text { scope can be certified by testing protocol and safety analysis validated by third parties, } \\
\text { national or international laboratories. }\end{array}$ \\
\hline Fire-safety engineering & $\begin{array}{l}\text { The designer must apply fire-safety engineering methods by means of assumptions and } \\
\text { limits provided for by national and international fire engineering practice, according to } \\
\text { the procedures set out in the chapters M1, M2 and M3 of the IFC. }\end{array}$ \\
\hline
\end{tabular}




\subsection{M2, performance-based approach for design fire scenarios}

The chapter M2 contains the guidelines for the identification and the choice of the design fire scenarios to be used for "quantitative analysis". Initially a large family of fire scenarios including all the possible outcomes that can take place must be evaluated, starting with the actual operating conditions but also taking into account fire events that have previously occurred in similar characteristics and occupancies. Given the initiating event, an event tree analysis [17], [18], is required fixing the boundary conditions that influence fire spread, activation of technological safety systems, human behavior and so on. By the event tree a more representative number of design fire scenarios should be selected, coherently with the safety objective stated in the "preliminary analysis" [19]. For example, if the safety objective is the maintenance of the fire resistance for a long time, the selected design fire scenarios will probably comprise a slow growth phase but an overall long duration; on the contrary, if safe evacuation needs to be guaranteed, a scenario of fast fire with high production of toxic gases, must be chosen to be on the safe side. The key parameter for the quantitative description of the fire is the Rate of Heat Release (RHR) curve, usually measured in $\mathrm{kW}$ : its choice requires special attention. In fact, together with $\mathrm{CO}$ (carbon monoxide) and particulate production (soot), the RHR curve strongly influences the maximum temperature as well as the spread development of smoke to other compartments. For many cases the RHR curve can be estimated through the well-known quadratic growth phase, followed by a constant stationary phase and a linear decay at the end [20]. However, if the previous description is not considered to be representative of the real fire evolution, the RHR curve can be calculated by evaluating the spread of fire from one object to another by thermal radiation [21], [22], although in this case it is necessary to know the parameters that govern the ignition. Alternatively, the IFC also provides pre-determined fire scenarios for both civil and industrial activities, ready to be applied without more specific analysis, including a description of the maximum RHR, CO yield and soot production.

\subsection{M3, performance-based approach for life safety}

The chapter M3 finally contains some details for the application of performance-based approach methods for life safety. To design the means of egress, the performance criterion to be verified is that the Available Safe Egress Time (ASET) shall be longer than the Required Safe Egress Time (RSET) for all the evacuees. Specifically, the ASET is the time between the trigger of the fire and the time when the environmental conditions become untenable for occupants, probably unable to reach a safe place because intoxicated. This term can be estimated by means of computational fluid dynamics (CFD) models such as, for example, FDS (Fire Dynamics Simulator) [23]. The evolution of gas temperatures and toxic concentrations can be numerically calculated in the domain crossed by the occupants. Alternatively, a conservative simplified method called "zero exposure" can be adopted, by verifying, as safety thresholds, that the upper hot gas layer not exceed $200^{\circ} \mathrm{C}$ and is not higher than $2 \mathrm{~m}$ from the floor. The term RSET is instead the time between the triggering of the fire and the time when the last occupant has reached a safe place. This value can be derived by the evacuation models. Once the behavioral scenarios are defined, the RSET value can be expressed as the sum of several components: detection time, alarm time, pre-evacuation time and movement time. The movement time is strongly dependent on the geometry of the building and the human speed (decreasing in presence of smoke), whereas the pre-evacuation time is affected by a wide array of aspects. Some aspects are related to the actual use of the premise (type of occupants and familiarity with the means of egress) but past experiences, 
personal attitudes, presence of groups and herding behavior can play a key role in case of emergency. It must be highlighted that nowadays not all these features can be inserted in the evacuation models [24]. The difference between ASET and RSET is the margin of safety $t_{\text {marg }}$, whose magnitude depends on the reliability of the input data concerning both fire and evacuation modelling. In general, IFC except specific cases, obliges verifying that the margin of safety is greater than the Required Safe Egress Time ( $t_{\operatorname{marg}} \geq 100 \%$ RSET). Nevertheless, with particularly reliable input data such as evacuation parameters chosen from a real egress drill, it is possible to verify that the margin of safety is greater than ten percent of the Required Safe Egress Time $\left(t_{\text {marg }} \geq 10 \%\right.$ RSET).

\section{CONCLUSIONS}

The resent paper describes the structure of IFC that is consistent with the international state of the art of fire safety science and engineering. Compared with traditional prescriptive fire regulations, the performance-based approach implies a wide range of advantages, such as flexibility in the choice of the most appropriate design solution consequent to a more realistic definition of fire scenarios. However, the performance-based design requires more expertise and knowledge in this field, especially when numerical fire or evacuation models are needed. In this case, in fact, the sensitivity of the designer can strongly affect the results and therefore the proposed solution. Moreover, the IFC risk-based fire design approach applied to complex and challenging fire protection problems leads to design solutions that provide performance superior to the prescriptive ones. At the same time the undesirable or unworkable features due to the strict compliance with the prescribed design are avoided. These improvements are usually achieved by integrating all of the fire protection systems rather than designing each isolated device.

The challenge of the next few years will be to guarantee the reliability of the integrated technology systems according to the RAMS approach (i.e. Reliability, Availability, Maintainability and Safety) in order to improve safety performance.

\section{REFERENCES}

[1] Decree of the president of the republic, 1 Aug. 2011, no. 151. Regulations for simplified application of the discipline procedures relating to fire prevention activities.

[2] Wolski, A., Dembsey, N.A. \& Meacham, B.J., Accommodating perceptions of risk in performance-based building fire safety code development, Fire Safety Journal, 34, pp. 297-309, 2000.

[3] Decree of the minister of the interior 3 August 2015 Approval of fire prevention technical standards, pursuant to Article 15 of Legislative Decree 139 of 8 Mar. 2006.

[4] BS 9999:2008 Code of practice for fire safety in the design, management and use of buildings, British Standards Institution (BSI), http://www.bsigroup.com/.

[5] NFPA 101 Life Safety Code, National Fire Protection Association http://www.nfpa.org.

[6] International Fire Code 2009, International Code Council http://www.iccsafe.org/.

[7] Guarascio, M., Lombardi, M., Rossi, G. \& Sciarra, G., Risk analysis and acceptability criteria. WIT Transactions on the Built Environment, 94, 2007.

[8] Spinardi, G., Fire safety regulation: Prescription, performance and professionalism. Fire Safety Journal, 80, pp. 83-88. 2016.

[9] Senez, P., Calder, K. \& Coles, A., Alternative Solutions and Acceptable Risk, A Canadian Context Origins of the National Building Code of Canada, Richmond, WPI, Worcester, 2012. 
[10] Siemon, M., Albrecht, C. \& Hosser, D., Considerations for the development of a quantitative life safety design concept using performance based fire engineering methods, in: Proceedings of the 9th International Conference on Performance.

[11] Weyenbergea, B.V., Crielc, P., Deckersa, X., Caspeelec, R. \&. Mercia, B., Response surface modelling in quantitative risk analysis for life safety in case of fire, IAFSS 2017 conference proceedings.

[12] ISO 23932:2009, FSE - General principles.

[13] ISO/TR 13387-1:1999 FSE - Part 1: Application of fire performance concepts to design objectives.

[14] BS 7974:2001 Application of FSE principles to the design of buildings - Code of practice.

[15] BS PD 7974-0:2002 Application of FSE principles to the design of buildings - Part 0: Guide to design framework and FSE procedures.

[16] SFPE Engineering Guide to Performance-Based Fire Protection, 2nd ed., 2007.

[17] ISO 16732-1 Fire safety engineering - Fire risk assessment.

[18] NFPA 551 Guide for the evaluation of fire risk assessment.

[19] ISO/TS 16733 Fire safety engineering - Selection of design fire scenarios.

[20] Eurocode 1 UNI EN 1991-2:2004 Part1-2 Action for fire resistant structures.

[21] NFPA92 Standard for smoke control systems.

[22] NFPA555 Guide on methods for evaluating potential for room flash over.

[23] McGrattan, K.B. et al., Fire Dynamics Simulator (Version 6)-Technical Reference Guide. NIST Special Publication 1018-5, National Institute of Standards and Technology, Gaithersburg, USA, 2008.

[24] Kuligowki, E.D. et al., A review of building evacuation models, 2nd ed., NIST Technical Note 1680, 2010. 